\title{
IDENTIDADES E ALTERIDADES GUERREI- RAS: UMA ANÁLISE COMPARADA ENTRE HOMERO E EURÍPIDES
}

Bruna Moraes da Silva ${ }^{1}$

\begin{abstract}
Resumo: Propomos, no presente artigo, analisar através da Iliada, de Homero, da Ifigênia em Áulis e da Fenícias de Eurípides, as identidades e alteridades do guerreiro na Antiguidade arcaica e clássica, isto é, as maneiras de como se agir e não se agir em campo de batalha. Partindo da metodologia de Marcel Detienne para a História Comparada e da Análise de Discurso Francesa, iremos destacar como a epopeia e as tragédias investigadas detinham um papel formativo dentro da sociedade em que se inseriam, levando aos seus públicos os ideais bélicos a serem seguidos ou rechaçados.
\end{abstract}

Palavras-chaves: Identidade, alteridade, guerreiro, Homero e Eurípides.

Diversos autores da Antiguidade grega foram responsáveis por compilar em suas obras conflitos bélicos. Epopeias, tragédias e a incipiente historiografia traziam como temática não apenas os desdobramentos das guerras, mas também o éthos ${ }^{2}$, a identidade guerreira, isto é, a maneira pela qual aqueles que enfrentavam o inimigo em campo de batalha deveriam, ou não, portar-se.

Desde Homero, autor que analisamos no presente artigo, verificamos através de heróis como Aquiles, Heitor e Menelau, os parâmetros a serem seguidos por aqueles que ouviam suas narrativas e que com ela entraram em contato nos períodos posteriores. Não é sem motivo que esses heróis serviram de inspiração para tragédias - também alvos de nossa investigação -, nelas sendo protagonistas ou personagens essenciais ao enredo ${ }^{3}$.

1 Mestre em História Comparada pelo Programa de Pós-Graduação em História Comparada da UFRJ. Doutoranda em História Comparada pela mesma instituição. E-mail: bruna.histoire@ gmail.com.

2 Segundo o dicionário etimológico de Chantraine (1968, p. 327), o termo éthos tem por significado "hábito", "costume”.

3 As obras homéricas eram arquitextos para toda a tradição literária posterior a elas, ou seja, portadoras de "um estatuto exemplar, que pertencem ao corpus de referência de um ou de vários posicionamentos de um discurso constituinte" (CHARAUDEAU; MAINGUENEAU, 2012, p. 64). 
Todavia, ao desvelar diferentes códigos de conduta do guerreiro, a literatura antiga não punha em evidência apenas as ações consideras dignas de um aristoí ou de um cidadão-soldado, mas também demonstravam maneiras de como não se agir, as transgressões a esses códigos, alteridades dentro de um mesmo seio social. À vista disso, propomos, no presente artigo, analisar a partir dessa literatura - mais especificamente da Ilíada, de Homero, e da Ifigênia em Áulis e Fenícias, de Eurípides, como o valor pedagógico dessas obras dava-se igualmente através de exemplos negativos, de uma "vulnerabilidade à norma ideal expressa pela sociedade” (REDFIELD, 1994, p. 116), podendo isto ser verificado como um recurso paidêutico inerente aos discursos analisados ${ }^{4}$.

Partiremos dos requisitos metodológicos de Marcel Detienne para realizar essa análise comparada ${ }^{5}$, sendo as identidades e alteridades guerreiras o nosso comparável. Ademais, pautaremos a investigação da documentação nas prerrogativas da Análise de Discurso Francesa, buscando ir além de uma análise per se do discurso, colocando-se em destaque os processos e condiçóes de produção do mesmo, pois "o analista de discurso relaciona a linguagem à sua exterioridade" (ORLANDI, 2012, p. 16).

Em relação aos conceitos de identidade e alteridade, podemos ver que eles não marcam apenas o debate entre conflitos étnicos, mas também status e papeis sociais dentro de um mesmo grupo. Como nos é salientado por JeanFrançois Dortier (2010, p. 283), há uma identidade social, estatutária, em que o sujeito assume posições na comunidade seja pela idade (criança, adolescente, adulto...), pelo lugar na família (esposo, esposa, filho...), pelo sexo (homem ou mulher) e até mesmo pela profissão (médico, advogado, professor...). Essas posições se relacionam com papeis e códigos sociais culturalmente estabelecidos, isto é, espera-se determinados comportamentos desses sujeitos. "A identidade, o 'eu', é constituída do conjunto das imagens que os outros nos enviam e que

4 O termo paidêutico deveria de paideía, conceito amplo e complexo que, literalmente, pode ser compreendido por educação de meninos, mas que pode ser compreendido como um conjunto de atividades educacionais e culturais da sociedade grega, que visava a construção de um cidadão com areté (excelência, virtude), honra e coragem, através de atividades que levavam a harmonia entre o corpo e a mente.

5 Marcel Detienne, em sua obra Comparar o incomparável (2000) evidencia tanto conceitoschave para se analisar comparativamente. Para o autor, produçôes culturais, costumes, leis, mitos e ritos, devem ser o foco da investigação dos pesquisadores, o helenista enfatiza que através do estudo comparado devemos nos tornar tão familiares do pensamento ou da cultura analisada, que possamos "fazer como se nela estivessem, como se pensassem com aquele pensamento" (DETIENNE, 2000, p. 44). A partir disso, propóe alguns procedimentos metodológicos a serem seguidos, como é o caso da construção de comparáveis que, nas palavras do autor, são relações em cadeia com uma escolha inicial (DETIENNE, 2000, p. 58), ou seja, problemas definidos a partir do que se deseja analisar, de uma categoria estabelecida pelo pesquisador. 
interiorizamos". Toda identidade do sujeito é uma representação do vínculo social do qual faz parte. Ela é relacional, simbólica e social (WOODWARD, 2000, p. 09 e 10). A partir das representaçóes sociais criadas pela/na sociedade que se dá sentido ao que somos ou o que podemos nos tornar.

Através da Análise de Discurso, vemos que essa identidade social também pode ser compreendida como identidade de posicionamento, ou seja, a posição que um sujeito ocupa em um campo discursivo em relação ao sistema de valores que o circulam: a identidade resulta "das condições de produção que exercem coerções sobre o sujeito, condições que estão inscritas na situação de comunicação e/ou no pré-construído discursivo" (CHARAUDEAU; MAINGUENEAU, 2012, p. 267). Destarte, defendemos que havia uma identidade social/cultural partilhada entre aqueles que iam a guerra na Antiguidade grega, vista através de afirmaçóes discursivas que perpassam as epopeias e tragédias.

Outrossim, conforme elucidado pelo antropólogo Marc Augé, a identidade somente pode ser produzida pelo reconhecimento do outro. A identidade e alteridade se completam em um seio social: elas o constituem e o definem (AUGÉ, 1998, p. 10, 19 e 20). Conforme nos é ressaltado por François Hartog, há um saber compartilhado entre os gregos, afirmado através do discurso, que constrói retóricas de alteridade: "Não há mais $a$ e $b$, mas simplesmente $a$ e o inverso de a" (HARTOG, p. 39 e 230). De acordo com Jean-Pierre Vernant, a identidade social deve ser compreendida como um modelo, um ponto de referência para se pensar o outro (VERNANT, 2002, p. 59).

Aprofundando-se acerca do que é ser o outro, Marc Augé o define em quatro categorias: 1) o Outro exótico, que é delineado a partir de um "nós" supostamente idêntico, isto é, de um grupo que se reconhece como uma unidade cultural, social, política (nós brasileiros, europeus, ocidentais); 2) o Outro étnico ou cultural - visto em uma relação "nós e eles", definindo-se "o que é" a partir do "que não é", como é o caso dos gregos frente aos bárbaros; 3) o Outro social - que se define pela posição assumida dentro de um mesmo sistema (a mulher, a criança, o escravo, o transgressor) e o Outro íntimo, que está presente em todos os sistemas sociais, remetendo-se as múltiplas identidades neles existentes (AUGÉ, 2008, p. 22-3).

No presente artigo, trabalharemos com a noção de outro social, visto que analisamos a identidade de um grupo específico (dos guerreiros), dentro de uma sociedade específica (a Grécia arcaica e clássica), dando destaque às transgressões existentes nesse sistema analisado. Como ressaltado por 
Maria do Céu Fialho, o outro não é apenas o bárbaro ou o estrangeiro, mas "a identidade helênica conhece tensões, fissuras e oposições de alteridades internas no seu seio - o Outro pode, também, ser o Grego, como rival, inimigo, invasor, infrator de códigos de comportamento" (FIALHO, 2010, p. 114, grifos nossos).

Investigando primeiramente a Ilíada de Homero, verificamos que ainda que não possamos constatar uma definição fechada do que posteriormente será compreendido como sociedade helênica, já se faz possível verificar a consolidação de uma identidade coletiva, sendo esta criada concomitantemente ao fenômeno da colonização e da expansão gregas, iniciadas a partir do século VIII a.C. (FIALHO, 2010, p.116) .

Através de suas epopeias, constatamos como algumas tradições já eram tidas como universais ou pan-helênicas, como a xênia (hospitalidade), o respeito aos mais velhos, o culto aos deuses e os ideais guerreiros, analisados nesta pesquisa. Mesmo que não possamos verificar a presença de bárbaros nas obras homéricas, a alteridade se faz presente em suas obras, sendo vista através do contato com seres excepcionais, como os ciclopes e as sereias, na Odisseia, nas relações de gênero, no embate com o inimigo e nas ações indignas dos heróis, temática que iremos analisar.

Assim, já havia um discurso de alteridade, do que era ou não era ser grego. Através do episódio do cíclope, por exemplo, visto no canto IX da Odisseia, verificamos que o protagonista define as características que marcam a helenicidade: seguir um código de leis, utilizar a terra para a agricultura, viver em comunidade, cultuar os deuses e serem "comedores de pão".

Em relação a identidade guerreira presente na Ilíada, podemos dizer que ela foi a primeira na tradição grega a nós legada a descrever os ideais esperados em campo de batalha. Valores como coragem, virtude, honra e vergonha deveriam ser seguidos ou rechaçados até mesmo na hora da morte. Os combates eram realizados de acordo com os valores cívicos dos aristoí, uma elite que fazia conexões entre suas próprias famílias e o passado mitológico narrado nas epopeias. Desse modo, o aedo utilizava-se da identidade ética específica deste grupo, especialmente daqueles que detinham o título de rei-

6 Apesar de todo debate acerca da datação obras Ilíada e Odisseia, assim como a existência de um indivíduo Homero, localizamos a criação do aedo, assim como grande parte dos homeristas, no século VIII a.C. Isso porque, ainda que em suas epopeias seja narrada uma época anterior a que teria vivido - o período Palaciano (XVII - XII a.C.) - ele não deixa de imiscuir em suas obras questões do seu cotidiano, sendo visto diferentes costumes arcaicos fazendo parte da vida dos heróis mitológicos, como é o caso da incipiente iségoria nas assembleias aqueias; a contestação dos reis, sendo seu poder alvo de disputas e discussão; a expansão para o mar e o contato com diferentes povos, conectando-se ao caráter proto-colonizador de Odisseu (MALKIN, 1998, p. 3). 
basileús ou ánax -, para estimular o ardor dos combatentes, encorajando-os e repreendendo-os quando necessário. Os aristocratas tornavam-se, assim, lóci privilegiado para a existência daqueles que são tidos na tradição como heróis.

No século $\mathrm{V}$ a.C., período em que as obras de Eurípides foram escritas, ainda que não houvesse diferenças acentuadas entre o seu respectivo portar-se guerreiro e aquele dos épicos - sendo possível verificar inúmeras similaridades -, a denominação de herói passa a ser suprimida pela de cidadão-soldado. Era este que iria se destacar na guerra em oposição ao antigo núcleo hermético e privilegiado dos aristocratas. A elite ateniense empregava os valores e trivialidades da poesia épica para representar seus próprios feitos guerreiros, travando suas guerras com a mesma intensidade e modus operandi da era dos heróis (PRITCHARD, 2014, p. 8, 14 e 38).

O bóplita passa, assim, a ser marcado por características que o diferenciam do guerreiro homérico em certos aspectos, especialmente àqueles que relacionam o seu papel em campo de batalha aos modelos político-culturais da época em que estavam inseridos. A formação hoplítica, além de promover mudanças nos armamentos, táticas de guerra e a inclusão de uma força bélica que não a aristocrática, dando abertura a outras camadas da sociedade ( $\mathrm{RICH}$; SHIPLEY, 1995, p. 47), foi uma resposta à necessidade de uma comunidade que cada vez mais abria espaço para o to koinón, o comum, o coletivo.

Relacionando o texto ao contexto, dessuperficializando-o, prerrogativa da Análise de Discurso, podemos verificar que as obras de Eurípides reverberavam os ideais políticos e guerreiros de sua época. Todavia, a maneira pela qual o poeta levava ao seu público essas temáticas era peculiar em relação aos tragediógrafos que junto a ele se destacaram por suas obras: Ésquilo e Sófocles. A característica do "mais trágico dos trágicos", tal como Aristóteles o denominara (ARISTÓTELES, Poética, XIII, 1453a, 29-30), era pôr no palco agôn ${ }^{7}$, o embate entre os ideais do discurso homérico, voltados à aristocracia, e aqueles preconizados na pólis democrática. Isto demonstrava a utilização da ambiguidade como meio de expressão do universo trágico, visto que, segundo Mills, "a tragédia pode, de fato, questionar uma ideologia, mas a ambiguidade no seu centro sempre oferece uma rota de escape" (MILLS, 2014, p. 183). As obras eram, assim, tanto respostas críticas à democracia quanto compartilhavam suas ideologias. Isso era facilitado pela liberdade pessoal e o debate aberto que a pólis ateniense proporcionava (PRITCHARD, 2014, p. 5).

7 Segundo Romilly (1999, p.39), “no agôn, cada um defendia o seu ponto de vista com toda força retórica possível, num grande desdobramento de argumentos que, naturalmente, contribuíam para esclarecer o seu pensamento ou a sua paixão". 
Igualmente, a valorização da guerra como meio de alcance da areté é deixada em segundo plano nas obras euripidiana e o destaque é dado à violência do conflito, assim como à hýbris (desmedida) e à harmatía (falha) de seus heróis, que se relacionam com os desmandos da pólis ateniense durante a guerra. Além da stásis, na qual gregos atacavam gregos, aumentava-se cada vez mais os números de atentados atrozes, tendo a Guerra do Peloponeso, como destaca Donald Kagan, rompido "a tênue fronteira que separa a civilização da selvageria” (KAGAN, 2006, p. 22). Eurípides, assim, representava através de suas personagens os erros humanos na guerra e também as vantagens da paz (PRITCHARD, 2014, p. 43). Desse modo, grande parte das alteridades internas verificadas em suas obras, os outros sociais apresentados pelo poeta, são referentes às ações dos comandantes de guerra helenos, como veremos através de Agamêmnon e Etéocles ${ }^{8}$.

Isto posto, em relação ao binômio identidade/alteridade, podemos verificar que os guerreiros representados por ambos os autores construíam sua identidade a partir de um sistema de regas que a sociedade impóe a si mesma, que a constitui e regula. E, tal como ressaltado por John Peristiany (PERISTIANY, 1995, p. 9), todas as sociedades regulam as leis de conduta, premiando os que as seguem e punindo os que as quebram.

Eric Dodds (2002) se refere a este tipo de organização social, especialmente a verificada em Homero, como uma shame culture (cultura da vergonha) em oposição a uma guilt culture (cultura da culpa). Enquanto esta tem mais a ver com aquilo que o indivíduo pensa de si mesmo - às suas sanções internas -, aquela se relaciona ao que os outros pensam dele, isto é, os impulsos individuais são coibidos e há uma pressão de adaptação social.

Em ambos os períodos analisados (arcaico e clássico) haveria a fundamentação das ações sociais em uma ética agonística, termo derivado de um processo de aportuguesamento, cuja base etimológica é a palavra agón, que caracterizava a sociedade helênica no que diz respeito à noção de competição (SOUSA, 2012, p. 31). Havia, assim, uma publicidade das açóes, na qual o sujeito seria sinalizado por seus iguais quando cometesse atos indignos, e/ou reverenciado quando realizasse atos honrosos, estando a identidade guerreira pautada em cumprir certas expectativas sociais.

8 Uma questão marcante nas obras euripidianas é o fato de a identidade helênica guerreira ser muitas vezes demonstradas por personagens femininas, transformadas em heroínas ao se aproximarem dos ideais viris do hóplita em campo de batalha. As mulheres, segundo Sartre (2013, p. 20), poderiam manifestar sua andreía, especialmente em obras literárias, sendo a escolha por personagens femininas e até mesmo crianças, relacionada à fragilidade de suas condiçóes sociais, objetivando-se provocar a kathársis, a purgação das emoções (ARISTÓTELES, Poética,VI, $1449 b)$. 
Dentre essas expectativas estava, por exemplo, a timé ( $\tau 1 \mu \eta ́)$, usualmente traduzida por honra e status ${ }^{9}$ e entendida como o valor de uma pessoa frente aos próprios olhos e aos olhos dos outros, isto é, dependia tanto do reconhecimento pessoal do sujeito quanto do da sociedade. $\mathrm{O}$ guerreiro poderia tanto ser apontado pelos atos dignos ou pelos desonrosos, ainda que destes pudesse se redimir: sabendo que os outros o aprovam, ele irá aprovar a si mesmo.

O aidós também se destacava como ideal constitutivo da identidade dos guerreiros arcaicos e clássicos, podendo ser compreendido como o "medo da desaprovação ou da condenação pelos outros que faz um homem ficar e lutar bravamente". Assim como a honra, é um conceito individual e coletivo. Diz respeito a um sentimento de reserva e moderação, um páthos, um impulso emocional que se refere à realização de um comportamento corretamente e de acordo com o que se espera pelo outro, como se fora um freio para manter o equilíbrio (SCHEIN, 1984, p. 177).

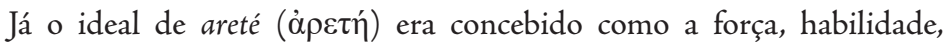
coragem, rapidez, sabedoria, destreza e poder de persuasão, igualmente definindo-se como o mérito ou qualidade pela qual o herói se destacava. Se um guerreiro hesita, se ele transgride valores éticos, ele será apontado pela sociedade como indigno de ser rememorado. A falta de areté era é descrita como uma falha, um erro (kakótes), trazendo uma má reputação e desonra (atimía) (WESS, 1992, p. 69), podendo o sujeito que não seguisse essa e outras normas guerreiras, ser considerado como o outro.

Unida à areté - sendo até mesmo com a ela confundida (BALOT, 2014b, p. 92) - a andreía ( $\alpha \nu \delta \rho \varepsilon i ́ \alpha)$, usualmente traduzida por coragem, força e vigor, destacava-se como um dos principais valores para ao guerreiro da Antiguidade grega, seja ele arcaico ou clássico. Ela pode ser compreendida como uma virtude positiva que visava um fim justificado. No campo de batalha, a andreía estaria conectada à capacidade do guerreiro de "superar o medo a fim de alcançar uma meta pré-concebida" (BALOT, 2004, p. 407).

Todavia, a coragem vista na sociedade ateniense diferencia-se daquela notabilizada nas epopeias ou entre os espartanos, havendo uma democratização da tradicional kalokagathia (nobreza) aristocrática (BALOT, 2004, p. 94). A andreía passa a assumir mais um caráter político que guerreiro, sendo louvado uma coragem que "não tem objetivo senão aquele de formar um cidadão

9 Devemos destacar que outras palavras são utilizadas na documentação analisada para definir a honra do guerreiro, como $\kappa \alpha \lambda o ́ \varsigma$ (kalós) - belo, grande, beleza moral, honra, glória, virtude (BAILLY, s.v. kalós) e $\dot{\varepsilon} \sigma \theta \lambda o ́ s$ (estblós) - justo, honesto, corajoso, viril (BAILLY, s.v. estblós). 
perfeito, mestre da palavra, dispensador de bons conselhos" (SARTRE, 2013, p. 21). Desse modo, haveria uma progressão natural entre a andreía guerreira e a andreía politiké. Ser corajoso passa a ser não simplesmente uma questão de desafiar o perigo, mas igualmente de como e por que o guerreiro o faz (BALOT, 2014, p.100).

Finalmente, a identidade guerreira seria consumada através da morte juvenil em batalha, demonstrando-se toda virilidade, honra e coragem. Nesta modalidade de morte, os homens acatam o seu destino, mesmo que seja trágico, fazendo de seu padecimento uma resposta à fatalidade do fim da vida, positivando-o através da memória e de uma nova condição de existência social. Para tal, não era necessário apenas perecer em combate, mas também receber honras fúnebres, dignas do guerreiro.

Estes, entre outros valores, faziam parte dessa identidade guerreira e ajudavam a reforçá-la, mas, conforme explicitado, nem sempre eram seguidos. Muitas vezes, seja devido ao medo ${ }^{10}$, a hýbris ou a harmatía, o mesmo se tornava o outro.

\section{O outro social em Homero e Eurípides}

Investigando o caso homérico, verificamos, conforme suscitado por David Claus que "devemos distinguir (...) entre o sistema de valores homérico em si mesmo e as respostas dos heróis a ele" (CLAUS, 1975, p.27), ou seja, o código heroico existe, mas a maneira como cada um reage a ele não é predeterminada. Consoante às análises de James Redfield, podemos constatar que o poeta conhece as normas e também os desvios que se cometem em relação a ela, característica que será vista não apenas em suas personagens, mas também na audiência do aedo (REDFIELD, 1994, p. 81). Em ambos os casos, verifica-se que cada situação de desequilíbrio ocasionada deve ser revertida pelo guerreiro através de atitudes nobres que a eles cabem.

As falhas do herói homérico são constantemente conectadas à áte e à hýbris. A primeira diz respeito à perdição, à ruína e à cegueira que pode

10 Os guerreiros tinham medo, erravam, mas isso não significava que perderiam para sempre sua identidade. Tanto a coragem quanto o medo poderiam coabitar o mesmo indivíduo, visto que este é corajoso à medida que a coragem sobrepuja o medo; e covarde quando o medo sobrepuja a coragem. Não podemos, assim, afirmar que um guerreiro é totalmente destemido, assim como que ser covarde seja sinônimo de sentir medo: a covardia implica, também, na recusa total à batalha e o não retorno numa situação de fuga. Segundo Aubreton, "é o temor que faz o herói estar alerta" e "os heróis de Homero se distinguem da multidão, não porque não têm receio, mas porque tremem menos" (AUBRETON, 1956/1968, p. 233 e 235). 
atingir o sujeito. Para Eric Dodds, é "uma situação de insanidade" causada não por questões fisiológicas ou psicológicas, mas por uma intervenção externa, de deuses ou daimones"11 (DODDS, 2002, p. 13). Já a segunda tem por significado "desmedida", "uma violência injusta provocada pela paixão, violência, desmesura, ultraje a uma pessoa” (CHANTRAINE, s.v. hýbris).

Agamêmnon, líder da expedição aqueia, é uma das personagens da Ilíada que se encontra em estado de áte durante a trama (HOMERO, Ilíada, II, v. 111) e acaba por cometer atos indignos, consequência da privação do géras (privilégio) de Aquiles, pois o basileús de Micenas toma para si a escrava troiana Briseida do Pélida, fazendo com que este se afastasse da guerra.

Ao constatar a situação de perdição em que se encontra (HOMERO, Ilíada, IX, vv. 17-9), Agamêmnon suplica a Aquiles seu retorno ao campo de batalha - visto que o lado aqueu vinha enfrentando muitas perdas -, mas este ignora. Todavia, impedir que a áte de outrem seja eliminada com a recusa de uma súplica acaba por gerar um estado de áte no próprio Aquiles. À vista disso, analisando a personagem do herói, podemos verificar que apesar de se tratar de um protótipo do herói aristocrático, marcado sua destreza, força, proezas sobre-humanas e origem semidivina ${ }^{12}$, é ele que mais se destaca por cometer atos indignos de sua categoria.

Transgressor de normas, conhecido desde o início da epopeia Ilíada como o herói da ménis (ira) e da hýbris, ele desrespeita códigos helênicos guerreiros, chegando a ser denominado pelo aedo de ágrios anêr, homem selvagem (HOMER, Ilíada, XXI, v. 314). Desde o início da epopeia, a personagem é marcada pelo seu caráter questionador: ele contesta e ataca o líder Agamêmnon (HOMERO, Ilíada, I, vv. 149-171 e 225-245), descrito por Nestor como aquele "quem pode mais" e "reina sobre mais gente" (HOMERO, Ilíada, I, v. 281); inquiri os deuses sobre os seus poderes e objeta acerca da necessidade de uma morte gloriosa e o ganho de honra em batalha. Como verificamos no canto IX, para o herói

Não há recompensa

no incessante combate contra os inimigos;

11 Segundo Chantraine, o daimon diz respeito a uma potência divina que não é nominada ou não se deixa reconhecer (CHANTRAINE, 1968, p. 246).

12 Aquiles é uma personagem insigne nas epopeias homéricas, caracterizado por muitas vezes como quase inumano, como vemos nas falas de Odisseu (HOMERO, Ilíada, XIX. vv. 216-229), Fênix (HOMERO, Ilíada, IX.vv. 515-526) e Apolo (HOMERO, Ilíada, XXIV. vv.39-54), por exemplo. Tudo no herói é superlativo: ele é o mais rápido, o mais forte, o mais bravo e o mais temível entre todos os heróis do épico, sejam aqueus ou troianos. 
prestam honras $(\tau \varkappa \mu \tilde{n})$ iguais ao herói e ao poltrão;

morre tanto o pugnaz, como que nada faz;

Nada me adveio, após jogar a vida e tanto

Padecer, a lutar, expondo-me sem pausa

(HOMERO, Ilíada, IX, vv. 316-322).

Ao se queixar para mãe sobre o que Agamêmnon o causou, Aquiles pergunta: "Mãe, que me dotaste/ de uma vida tão curta, não devia o Olimpo/ cumular-me de honras ( $\tau 1 \mu \eta ́ v)$ ? Zeus, que no alto soa, / não me deu nem migalha" (HOMERO, Ilíada, I, vv. 352-5) ${ }^{13}$

Outro caso em que a desmedida de Aquiles se torna a protagonista é o momento que precede sua vitória contra Heitor. O Pélida ameaça ultrajar seu corpo (XXII, vv. 344-355/XVIII, vv. 336-7/XXIII, vv. 180-4), dizendo que a ele não será dado um funeral digno, característica essencial para que o guerreiro fosse rememorado pela sociedade. Mesmo com os pedidos de Heitor, que suplica pela alma, pelos joelhos e pelos pais de Aquiles por um funeral digno (HOMERO. Ilíada, XXII vv. 339-343), o filho de Tétis nega seus gèras thanónton, aquilo que é devido ao morto, realizando mais um ato de hýbris que destaca, inclusive, como "o destino do cadáver de Pátroclo encontrase absolutamente conectado ao de Heitor [...] um é inseparável do outro: o primeiro em excesso de honra, e o segundo em excesso de indignidade" (SCHNAPP-GOURBEILLON, 1982, p.83). Desse modo, tal como Seth Schein, concordamos que

A verdadeira ofensa de Aquiles ao purgar seu ódio e solidão no corpo de Heitor não é contra Heitor, mas contra a família e a comunidade que desejam chorá-lo e enterrá-lo. Ele está violando a necessidade social por partes dos vivos de enterrar os mortos com decoro ritual e formal, a fim de humanizar o fator morte e fazer isto mais tolerável (SCHEIN, 1984, p.188).

Seu ato é considerado reprovável até mesmo por parte dos deuses (HOMERO, Ilíada, XXIV, vv. 20-7), que conseguem não permitir que o corpo de Heitor fosse ultrajado. Apolo chega a denominar Aquiles de "mortífero" e como aquele que ignora o aidós, proferindo aos imortais que o herói

não tem juízo são na mente malsinada, nem é flexível de ânimo; selvageria

é só o que ele conhece, feito leão fortíssimo

13 Devemos ressaltar que o ato de Agamêmnon ou retirar Briseida de Aquiles é considerado um "roubo" da honra de Aquiles, que deve ser restituída (HOMERO, Ilíada, II, vv. 509-510) 
e soberbo, que, para saciar-se, ao rebanho

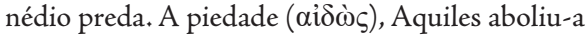

e a reverência, fausta ou funesta aos mortais.

[...]

Isso não é

bom, nem belo. Valente embora, tema Aquiles

que nós nos indignemos contra ele: furioso,

desandou a ultrajar um húmus já insensível!'

(HOMERO, Ilíada, XXIV, vv. 40-54).

Zeus igualmente se enfurece com as ações do herói, indo até Tétis ameaçá-lo caso o corpo de Heitor não fosse devolvido:

A teu filho refere a ira dos deuses; quanto, mais ainda, me enfureço: mente demente, ele retém, à beira-nau, irremisso, o cadáver de Héctor. Se ele me teme, vê que, pronto, o livre.

Mandarei a Príamo, Íris, a núncia, a dize-lhe que vá às naus aqueias, para remir o filho com dons que a Aquiles o ânimo acalentem' (HOMERO, Ilíada, XXIV, vv. 114-120).

Obedecendo as ordens do deus, Aquiles decide pela devolução do corpo de seu inimigo, redimindo-se de suas faltas e reavendo seu estatuto heroico, mesmo que isso só ocorra ao fim da Ilíada. A partir disso, Aquiles consegue se livrar da sua condição de outro, redimindo suas kakà érga e conseguindo sua reinserção social. Segundo Redfield, a história de Aquiles é de um homem que em determinados momentos rompe com as normas de sua sociedade. Todavia, ao fim, ele é novamente incluído nesta e a validade de suas normas é a reafirmada (REDFIELD, 1994, p. 10).

Outro herói apontado na Ilíada como desviante dos códigos de conduta apresentados pelo aedo e que acaba por se tornar uma alteridade interna é Páris. Conforme os estudos de Renata Cardoso de Sousa, verificamos que "é comum encontrarmos designações não tão heroicas a Páris vindo de helenistas contemporâneos", como "afeminado" e "frouxo" (LORAUX, 1988, p. 93), "não heroico" e "o mais desmerecido dos filhos de Príamo" (REDFIELD, 1994, p. 113 e 114). No entanto, não são apenas nas obras destes estudiosos que verificamos essas críticas ao príncipe troiano: Homero igualmente as faz através de suas personagens, que rechaçam os atos indignos do guerreiro em campo de batalha. Para Sousa,"o motivo principal é o fato de ele ter causado a guerra de Troia, mas Homero traz, além disso, a ideia dele não ser um guerreiro tão bom assim, o que gera reprimendas também" (SOUSA, 2014, p. 51). 
Desse modo, além de a ele ser creditado a causa da guerra (HOMERO, Ilíada, V, vv. 63-4/VI, vv. 280-5/XXII, vv. 115-6), um dos atos que destaca essa transgressão aos modelos a serem seguidos diz respeito a fuga de sua contenda com Menelau no terceiro canto da obra. Sua recusa em batalhar tem como consequência a repreensão de Heitor que se dirige a Páris dizendo:
'Ó mal-parido Páris, belo só nas formas, mulherengo, impostor! Não-nascido, sem-bodas
- penso - melhor seria, que servires de opróbrio e vexame perante os olhos de nós todos.
Hão de estar gargalhando os Gregos com seus longos
Cabelos. Persuadiam-se eles de que eras belo na forma, bom de guerra; és frouxo, pusilânime (HOMERO, Ilíada, III, vv. 43-45).

Até mesmo Helena demonstra sua insatisfação em relação às atitudes do herói: primeiramente, recusa-se a ir encontrá-lo, dizendo que seria vergonhoso deitar-se com ele (HOMERO, Ilíada, III, vv. 410-412). Após isso, ao com ele se defrontar, recrimina-o, tal como Heitor, por ter recuado do combate e o instiga a retornar:

\author{
'Voltaste da guerra? Quem dera \\ tivesses sucumbido à forte mão do meu \\ primeiro esposo. Vão, blasonavas vencê-lo \\ pelo vigor do braço e destreza na lança! \\ Vai, provoca de novo Menelau, dileto \\ -de-Ares, à luta, cara a cara. Não, melhor \\ parar. Não podes enfrentar o louro Atreide. \\ Louco! Um letal lançaço te fulminaria, \\ se o combatesses!' \\ (HOMERO, Ilíada, III, vv. 428-436).
}

A reprimenda de Helena surte efeito, ainda que sob críticas a Paris, afirmando que este "não é e não será jamais de firme/têmpera", dizendo a Heitor que gostaria de ser casada com um homem "de mais brio" (HOMERO, Ilíada, VI, vv. 350-353). Assim, temeroso do aidós que vinha sofrendo, o guerreiro retoma seu valor heróico ao decidir voltar e enfrentar Menelau, demonstrado que apesar de ter errado, ele deve reaver seu ato indigno.

Já em relação às transgressões vistas nas tragédias euripidianas, é possível constatar, conforme já citado, que elas se conectam, sobretudo, aos desmandos cometidos pelos líderes guerreiros: suas ações se assemelham as que eram vivenciadas na pólis ateniense, inserida na Guerra do Peloponeso. 
Diferentemente do período arcaico, em que obras de Homero foram compostas, no clássico já havia uma distinção clara entre o que era ser grego e o que era ser bárbaro. Todavia, ainda que haja esta dicotomia, podemos verificar, especialmente através de Eurípides, testemunhos da "barbarização" do próprio grego. Em um momento de crise para a póleis, vemos aqueles que deveriam agir de acordo com as normas helênicas se distanciarem delas, provocando atos que os afastam de sua identidade ${ }^{14}$, como seus personagens irão demonstrar.

Agamêmnon, por exemplo, é novamente visto como alguém que ultraja normas esperadas em sociedade. Na peça Ifigênia em Áulis, verificamos, através de seu enredo, a justaposição entre valores militares e a família (RABINOWITZ, 2008, p. 109). Agamêmnon, pai da personagem que intitula a obra e chefe dos guerreiros aqueus, é colocado diante de um dilema: sacrificar sua própria filha para que a deusa Ártemis permita que o exército consiga avançar sobre Troia, visto que uma calmaria acometia as frotas helenas. Durante todo este dilema, verificamos que o herói vacila em suas decisões e, por vezes, deixa de lado seu código ético.

A conversa entre o herói e seu velho escravo destaca um questionamento do primeiro sobre a real necessidade de se receber o atributo da honra que, como vimos, era essencial ao guerreiro. Este questionamento se dá no momento em que ele deve decidir, acerca do sacrifício de sua filha, ao passo que tem como resposta daquele que acumulou ao longo de seus anos muita experiência, uma forte reprimenda, dizendo-lhe o certo a ser seguido:

\section{AGAMEMNON}

Eu te invejo, velho, invejo qualquer mortal que passa, desconhecido pela fama, por uma vida sem perigo. Eu sinto menos inveja por aqueles

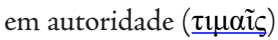

\section{VELHO}

Mas é lá que encontramos tudo o que é admirado na vida

\section{AGAMEMNON}

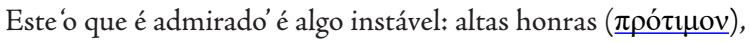
Embora doce, causam dor quando te atingem. Às Vezes os deuses não garantem sucesso, e em outros casos você É esmagado pelas opiniões dos homens, muitos e impertinentes como são.

14 Dentre os atos cometidos pelos líderes atenienses podemos destacar o ataque a ilha de Melos, no qual se levou a morte dos homens e a escravização de mulheres e crianças, e a expedição à Sicília, em que a autoridade do controverso líder Alcibíades é demonstrada. 


\section{VELHO}

Eu não aprovo estes tipos de sentimentos em um príncipe. Atreus

Não gerou você para uma vida apenas de bênçãos. Você deve sentir dor

Assim como prazer: você é mortal. Embora você não

Goste disso, este é o desejo dos deuses

(EURÍPIDES, Ifigênia em Áulis, vv. 17-34)

Este embate pessoal intrínseco à escolha do Átrida irá o acompanhar por grande parte da obra, sendo igualmente vítima de repreensões por seu irmão Menelau que diz ser lamentoso caso o sacrifício da jovem Ifigênia não fosse realizado. Negar-se a tomar atitudes deste tipo, optando por uma decisão tola, só traria insegurança à polis, constatação que leva o baliseus de Esparta a pronunciar que um general "deve ter inteligência” (EURÍPIDES, Ifigênia em Áulis, vv. 364-75). Assim, frente a reprimenda que recebe, opta pela salvação da Hélade, levando sua filha ao cutelo do degolador.

Outra peça que nos traz atos indignos de um grego é as Fenícias. Nela vemos o enfretamento entre dois irmãos: Polinices e Etéocles, filhos de Édipo, pelo controle de Tebas. Um dos debates posto em pauta pela peça é o apreço pela tirania - repudiada pela democracia ateniense -, por parte de Etéocles ${ }^{15}$, basileús tebano. Segundo suas palavras, ele

chegaria até as saídas dos astros do céu e baixaria o fundo da/terra, se fosse capaz de realizar tais ações, com o objetivo de/ preservar a maior das divindades: a Tirania. Assim, pois, /esse bem, mãe, não estou disposto a ceder-lo a outro em lugar/ de conserva-lo para mim. Covardia ( $\alpha \nu \alpha v \delta \rho i ́ \alpha)$ seria, de fato, deixar/ o melhor escapar, e conservar o pior [...] Sendo a mim possível exercer o poder, serei uma/ vez um escravo sujo? [...] Se é necessário violar a justiça, pela tirania/ é esplêndido violar-la (EURÍPIDES, Fenícias, vv. 504-510/520-1 e 525-6).

Frente ao seu discurso, críticas são expostas, como pelo Corifeu, que diz não ser conveniente "falar bem em favor de feitos não bons. Pois/ isso não é belo, mas sim amargo para a justiça” (EURÍPIDES, Fenícias, vv. 527-8). Sua mãe, Jocasta, igualmente o censura:

15 Devemos ressaltar que a tirania na Grécia Antiga não foi sempre conectada a uma valoração negativa. Apesar de verificarmos a tomada do poder político em proveito próprio, foram frequentemente atribuídas aos tiranos medidas destinadas a agradar os camponeses mais pobres, como partilha das terras, abolição das dívidas, empréstimos diversos, entre outros (MOSSÉ, 2004, p. 274). 
Por que te abandonas a pior das/ deusas, meu filho, a Ambição? Não, tu não! É injusta essa divindade. / Em muitas famílias e em cidades felizes ela se introduz e/ acaba destruindo aqueles que lá vivem. Por ela cometes loucuras. [...] Por que a tirania, uma injustiça prospera, estimas/ em extremo e a considera magnífica? Por que a vê com/ grandes honras?" [...] Olha, se eu, propondo-te uma dupla oferta, te perguntasse/ qual das duas coisas prefere: ser rei ou salvar a cidade/, vai dizer ser rei? E se te vence este? E se as/ lanças de Argos dominarem as lanças cadmeas? Verá essa/ cidadela tebana submetida, verá a muitas donzelas cativas/ ultrajadas com brutalidade pelos guerreiros inimigos. Causa/ de dores resultará a riqueza, a que você anseia conservar, / para Tebas, e você, ambicioso (EURÍPIDES, Fenícias, vv. 530-5/550-3 e 560-7).

Analisando estes versos em sua materialidade linguística, isto é, dando destaque ao como se diz, o quem diz e em que circunstâncias (ORLANDI, 2012, p. 65), defendemos que Eurípides realizava uma crítica ao momento por ele vivido, demonstrando através das censuras às decisóes bélicas de Etéocles, em prol da violência, como um líder não deveria agir. Conforme ressalta Romilly, muitas vezes "poderia suceder que a condenação às violências da tirania deva algo a uma inquietude precisa: a que começava a suscitar no mundo grego, e inclusive em Atenas, a violência do imperialismo ateniense" (ROMILLY, 2010, p. 48-9) e a sua aproximação com ideais tirânicos.

É através do próprio discurso de Péricles, por exemplo, que podemos verificar este dado. $\mathrm{O}$ estratego, ao expor que a guerra teria relação com a possibilidade de perda do poder sobre o outro, diz aos cidadãos que estes não podem renunciar a luta, pois "o que agora tendes é uma tirania, que talvez fosse injusto ter criado, mas é certamente perigoso eliminar" (TUCÍDIDES II, LXIII, 2).

O apreço de Etéocles à tirania igualmente pode ser conectado ao papel de Tebas ao longo da Guerra do Peloponeso: o de inimiga. Assim, não seria sem motivos que Eurípides colocaria seu líder conectado a características negativas, à audácia ao invés da prudência (EURÍPIDES, Fenícias, v. 559). Conforme ressaltado por Brian Kibuuka, "se Atenas geralmente aparece como lugar de acolhimento, de defesa da justiça e de isonomia, Tebas é uma inversão de tal perspectiva”. Ainda que seja parte do território helênico, ela é a antipólis, marcada pela ruína e desmedida que a própria história trágica de Édipo e seus familiares delineia (KIBUUKA, 2012, p. 85-6).

Isto posto, podemos verificar através das obras euripidianas, que seus versos trazem confrontamentos inerentes ao gênero trágico, aqui já expostos. Através do agôn, do debate entre princípios, a identidade helênica era destacava, tal como as alteridades dentro existentes dentro dela, as decisões a não serem seguidas, sendo este, tal como verificamos nas obras de Homero, um recurso 
discursivo e educativo do poeta, visto que veiculavam a ideologia guerreira aos seus ouvintes e espectadores, possuindo um papel efetivo em meio a estes.

Realizando-se uma análise comparada e dessuperficializando nosso corpus documental, verificando de onde o discurso parte, para quem ele se dirige e com que intuitos, foi possível verificar como, apesar de certas peculiaridades, as representações de ideais guerreiros afastados no tempo comungam códigos de conduta muito próximos em campo de batalha. Ser corajoso, não fugir do combate, buscar honra e glória são características que podemos aplicar aos gêneros aqui analisados, conciliando, como postulado por Marcel Detienne, uma reflexão atenta tanto às semelhanças quanto às diferenças e às particularidades, visto que que o discurso é um processo em curso, mas não um processo imutável.

Ademais, por atualmente vivermos em um tempo em que as diferenças, aquilo que não é aceito pela grande massa da sociedade, começa a pedir o seu lugar, faz-se mister trazer à tona o debate identidade/alteridade. Valores que antes eram encarados como verdades naturalizadas e absolutas estão sendo questionados e, ainda que a identidade seja vista como uma convenção social necessária, ela é ambivalente: "ao mesmo em que alimenta a ilusão de pertencimento, aponta a frustração de ser excluído" (MENEZES, 2010, p. 16). Assim, ser o outro é tarefa árdua, ainda no século XXI.

\begin{abstract}
We propose in the present article to analyze through the Iliad, of Homer, and the Iphigenia in Aulis and the Phoenician, of Euripides, the identities and otherness of the warrior in the archaic and classical Antiquity, that is, the ways of how to act and not to act in the battlefield. Starting from the methodology of Marcel Detienne for Comparative History and French Discourse Analysis, we will highlight how the epic and tragedies investigated had a formative role within the society in which they were inserted, leading to their public the ideals of war to be followed or rejected.

Keywordsः Identity, otherness, warrior, Homer and Euripides.
\end{abstract}

\title{
REFERÊNCIAS
}

\section{Documentação literária}

ARISTÓTELES. Poética. Trad.: Eudoro de Sousa. Lisboa: Imprensa Nacional Casa da Moeda, 1994.

EURÍPIDES. Iphigenia at Aulis. In: Bacchae, Iphigenia at Aulis and Rhesus. Trad.: David Kovacs. Cambridge: Loeb Classical Library - Harvard University Press, 2002. 
. Fenicias. Trad.: Luis Alberto de Cuenca. Madrid: Editorial Gredos, S.A., 2010.

HOMERO. Ilíada. Trad.: Carlos Alberto Nunes. São Paulo: Ediouro, 2009.

. Odisseia. Trad.: Trajano Vieira. São Paulo: Editora 34, 2012.

TUCÍDIDES. História da Guerra do Peloponeso. Trad.: Raul M. Rosado Fernandes e M. Gabriela P. Granwehr. Lisboa: Calouste Gulbenkian, 2013.

\section{Dicionários}

MOSSÉ, Claude. Dicionário da civilização grega. Rio de Janeiro: Jorge Zahar Ed., 2004 .

BAILLY, Anatole. Le Grand Baillyః Dictionnaire Grec/Français. Paris: Hachette, 2000

CHANTRAINE, Pierre. Dictionnaire Étymologique de la Langue Grecque: histoire dês mots - tome I. Paris: Éditions Klincksieck, 1968.

CHARAUDEAU, Pierre; MAINGUENEAU, Dominique. Dicionário de Análise do Discurso. São Paulo: Contexto, 2012.

DORTIER, Jean-François. Dicionário de Ciências Humanas. São Paulo: Editora Martins Fontes, 2010.

Bibliografia

AUBRETON, Robert. Introdução a Homero. São Paulo: DIFEL, 1956/1968.

AUGÉ, Marc. A guerra dos sonhosł exercícios de etnoficção. Campinas: Papirus, 1998.

- Não-lugares: introdução a uma antropologia da supermodernidade. Campinas: Papirus, 2008.

BALOT, Ryan K. Courage in the democratic polis. Classical quarterly. Cambridge: Cambridge University Press, v. 54, n. 2, 2004, p. 406-423. p. $73-106$.

. The dark side of democratic courage. Social Research, v. 71, nº. 1, 2014,

CLAUSS, David B. Aidos and the language of Achilles. Transactions of the American Philological Association, v. 105, 1975, p. 13-28.

DETIENNE, Marcel. Comparar o incomparável. Aparecida: Ideias e Letras, 2004.

DODDS, Erick R. Os gregos e o irracional. São Paulo: Escuta, 2002.

FIALHO, M. C. Rituais de cidadania na Grécia Antiga. In: LEÃO, Delfim F;; FERREIRA, José R.; FIALHO, Maria. Cidadania e paideia na Grécia Antiga. Coimbra: Centro de Estudos Clássicos e Humanísticos da Universidade de Coimbra, 2010.

HARTOG, François. O espelho de Heródoto: ensaio sobre a representação do outro. Belo Horizonte: UFMG, 1999.

KAGAN, Donald. A Guerra do Peloponeso. Rio de Janeiro: Record, 2006.

KIBUUKA, Brian G. Eurípides e a Guerra do Peloponeso: representações da guerra nas tragédias de Hécuba, Suplicantes e Troianas (Dissertação de mestrado). Niterói: UFF, 2012.

LORAUX, Nicole. Maneiras trágicas de matar uma mulher. Imaginário da Grécia Antiga. Rio de Janeiro: Jorge Zahar Editor Ltda., 1988. 
MALKIN, Irad. The Returns of Odysseus: Colonization and Ethnicity. Berkeley: University of California Press, 1998.

MENEZES, Tayana. D. A identidade social: uma análise teórica. Revista Prolíngua, v. 5, n. 2, 2010, p. 16-27.

MILLS, Sophie. Euripides and the limits of tragic instruction. In: PRITCHARD, David M. War, Democracy and culture in Classical Athens. Cambridge: Cambridge University Press, 2014.

NASCIMENTO, Joselita. Q. Patris e patriotismo em Homero e tirteuः um estudo comparado (Séc. VIII-VII a.C.) (Dissertação de Mestrado). Rio de Janeiro: PPGHC/UFRJ, 2015.

ORLANDI, Eni P. Análise de discurso: Princípios \& Procedimentos. São Paulo: Pontes Editores, 2012.

PRITCHARD, David M. The symbiosis between democracy and war: the case of ancient Athens. In: PRITCHARD, D. M. War, democracy and culture in Classical Athens. Cambridge: Cambridge University Press, 2014.

RABINOWITZ, Nancy S. Greek tragedy. Oxford: Blackwell Publishing, 2008.

REDFIELD, James M. Nature and culture in the Iliad: the tragedy of Hector. Durham/Londres: Duke University Press, 1994.

RICH, John., SHIPLEY, Graham. War and society in the greek world. London e New York: Routledge, 1995.

ROMILLY, Jacqueline. A tragédia grega. Lisboa: Edições 70, 1999.

. La Grecia Antigua contra la violencia. Madri: Editorial Gredos, S.A., 2010 .

SARTRE, Maurice. Virilidades gregas. In: CORBIN, Alain; COURTINE, JeanJacques; VIGARELLO, Georges. História da virilidade - vol. 1. A invenção da virilidade da Antiguidade às Luzes. Petrópolis: Editora Vozes, 2013.

SEBILLOTE-CUCHET, Violaine. Libérez la patrie! Patriotisme et politique en Grèce ancienne. Paris: Editions Belin, 2006

SCHEIN, Seth L. The mortal hero. Los Angeles: University of California Press, 1984.

SOUSA, Renata C. "Páris funesto, de bela forma, louco por mulheres, sedutor" e sua função paidêutica na Ilíada de Homero (Monografia). Rio de Janeiro: UFRJ, 2012.

. Páris épico, Páris trágico: um estudo comparado da etnicidade helênica entre Homero e Eurípides (séculos VIII-V a.C.) (Dissertação de Mestrado). Rio de Janeiro: UFRJ, 2014.

VERNANT, Jean-Pierre. Entre mito $\&$ política. São Paulo: Editora da Universidade de São Paulo, 2002.

WESS, Hans V. Status warriors‡ war, violence and society in Homer and history. Amsterdam: Gieben, 1992.

WOODWARD, Kathryn. Identidade e diferença: uma introdução teórica e conceitual. In: SILVA, Tomaz D. (Org.); HALL, Stuart; WOODWARD, Kathryn. Identidade e diferença: a perspectiva dos estudos culturais. Petrópolis: Vozes, 2000. 